\title{
How Payment for Research Participation Can Be Coercive
}

\author{
Joseph Millum, National Institutes of Health \\ Michael Garnett, Birkbeck College, University of London
}

\begin{abstract}
The idea that payment for research participation can be coercive appears widespread among research ethics committee members, researchers, and regulatory bodies. Yet analysis of the concept of coercion by philosophers and bioethicists has mostly concluded that payment does not coerce, because coercion necessarily involves threats, not offers. In this article we aim to resolve this disagreement by distinguishing between two distinct but overlapping concepts of coercion. Consentundermining coercion marks out certain actions as impermissible and certain agreements as unenforceable. By contrast, coercion as subjection indicates a way in which someone's interests can be partially set back in virtue of being subject to another's foreign will. While offers of payment do not normally constitute consent-undermining coercion, they do sometimes constitute coercion as subjection. We offer an analysis of coercion as subjection and propose three possible practical responses to worries about the coerciveness of payment.
\end{abstract}

Keywords: human subjects research; informed consent; international/global health; motivation; philosophy; research ethics

\section{INTRODUCTION}

Extreme Poverty. A pharmaceutical company plans a randomized controlled trial comparing a new blood pressure medication with a standard antihypertensive in a low-income country in Sub-Saharan Africa. The study does not offer substantial medical benefits to participants, and is not excessively risky. The prospective participants are offered a cash payment worth approximately $\$ 100$ for completing the study. Most people in the area are desperately poor, living on less than a dollar per day. One hundred dollars could feed their hungry children, buy essential medicines, or relieve household debt. The local research ethics committee reviewing the study is willing to approve it but requires the research team to reduce the level of compensation dramatically. According to the committee chair, such a payment would be "coercive."

It is common practice to pay people who enroll in medical research. Yet this practice often provokes concern, especially when the amount of money is large, the research is risky, or the study population is poor. ${ }^{1}$ One common objection to such payments is that they are coercive. Indeed, the idea that payment is sometimes coercive appears widespread among research ethics committee (REC) members, researchers, and regulatory bodies (Largent et al. 2012). Yet analysis of the concept of coercion by philosophers and bioethicists has generally favored the view that payment does not coerce, on the grounds that coercion necessarily involves threats, and proposals to pay people for things generally constitute offers (Wertheimer and Miller 2008).

In this article we aim to resolve this disagreement by distinguishing between two different but overlapping concepts of coercion. One, which we call consent-undermining coercion, primarily serves to mark out certain actions as impermissible and certain agreements as unenforceable. On this understanding of coercion, it follows from the fact that a token of consent was coerced that it is not fully voluntary and so is invalid. The other, which we call coercion as subjection, primarily serves to indicate a way in which someone's interests can be partially set back, a form of unfreedom whereby one person is subject to another person's foreign will. On this understanding of coercion, coerced tokens of consent need not be

This work was authored as part of the Contributor's official duties as an Employee of the United States Government and is therefore a work of the United States Government. In accordance with 17 USC. 105, no copyright protection is available for such works under US Law.

1. For an overview of ethical concerns about the use of inducements to motivate research participants and responses to these concerns, see Wilkinson and Moore (1997).

Address correspondence to Joseph Millum, Department of Bioethics, Clinical Center, National Institutes of Health, 10/1C118, 10 Center Drive, Bethesda, MD 20892, USA. E-mail: joseph.millum@nih.gov 
invalid. Instead, the claim that a person has been coerced points to a specific negative effect on her well-being.

We argue that while offers of payment do not normally constitute consent-undermining coercion, they do sometimes constitute coercion as subjection. We thereby propose a partial vindication of the widespread view that payment can be coercive. However, contrary to this view, our analysis shows that coercive offers do not impact the ethics of research studies by means of invalidating participants' consent; instead, they do so by altering the balance of a study's expected risks and benefits. We offer an analysis of coercion as subjection and, in view of it, propose three possible practical responses to worries about the coerciveness of payment.

Finally, we discuss the closely related ideas of undue inducement and exploitation. We argue that coercion as subjection is morally distinct from both-at least inasmuch as undue inducement concerns incentives that predictably trigger irrational decision making, and exploitation concerns taking unfair advantage of someone in a vulnerable bargaining position. This is because coercion as subjection essentially concerns neither irrationality nor unfairness, but unfreedom. In addition, we argue that recognizing the morally distinct phenomenon of coercion as subjection can help to improve our understanding of these other moral defects.

\section{COERCION AND PAYMENT}

Within the United States, the idea that payment to research participants can be coercive appears to be common, though not universal. Official guidance from the Food and Drug Administration on how institutional review boards (IRBs) should assess payment to research subjects states: "The IRB should review both the amount of payment and the proposed method and timing of disbursement to assure that neither are coercive or present undue influence" (USFDA 2016). Likewise, the Office for Human Research Protections says in its IRB Handbook:

The IRB should review both the amount of payment and the proposed method of disbursement to assure that neither entails problems of coercion or undue influence. Such problems might occur, for example, if the entire payment were to be contingent upon completion of the study or if the payment were unusually large. (OHRP 1993)

Many IRB members and researchers believe that payment can be coercive. The Emily Largent et al. survey of IRB members, researchers, and others involved with human subjects research found that $65 \%$ of respondents agreed that it would constitute coercion if research participants "will participate when otherwise they would not if offered payment" $(2012,4)$. When research participants "feel they have no reasonable alternative but to participate because offered payment," $82 \%$ agreed that it would constitute coercion $(2012,4)$.
It also seems common to believe that the greater the amount of payment, the greater the danger of coercion. Forty-two percent of the Largent et al. respondents rated themselves as "very concerned" by "substantial payment" versus $4 \%$ for "token payment" $(2012,3)$. Robert Klitzman quotes an IRB chair:

We used to not allow people to put a monetary amount on recruitment flyers, because we thought it was a little coercive: "You'll get \$20 if you participate." But we've concluded that a gift card for an hour interview is probably not particularly coercive. If you were to say, "We'll pay $\$ 600$ if we can take blood," that might be a little coercive. $(2013,8)$

A small number of academic bioethicists appear to share the view that payment for research participation can be coercive. For example, Ruth Macklin writes:

The reason for holding that it is ethically inappropriate to pay patients to be research subjects is that it is likely to be coercive, violating the ethical requirement that participation in research should be fully voluntary. (Macklin 1989, 3)

However, the majority of philosophers and bioethicists who have addressed this problem have concluded that payment does not coerce. According to the standard analysis (Berman 2002; Haksar 1976; Ryan 1980; Wertheimer 1987), coercion involves one person proposing to make another person worse off if he does not comply with her demand, with "worse off" understood as "worse off relative to his preexisting moral entitlements." On this view, therefore, a proposal is coercive only if it constitutes a threat to violate the other's rights, or to fail to discharge some duty owed to the other (Wertheimer and Miller 2008). ${ }^{2}$

Thus, the armed robber who demands "Your money or your life!" proposes to violate her victim's right not to be killed unless he hands over his money. Since her victim also has no reasonable alternative but to hand over his money, the victim is coerced. By contrast, suppose that a patient needs an appendectomy for acute appendicitis. His surgeon presents the consent form and tells him that unless he agrees to her proposed operation he is likely to die. Declining the surgeon's proposal might put this patient in just as much danger as the robber's victim. But here he has not been coerced. This is because the surgeon is not proposing to violate his rights. Indeed, to make the choices exactly parallel, if the surgeon charges him a fee for the surgery, he still will not have been coerced into handing over his money (provided that he has no right to receive the operation free of charge).

2. More specifically: "A coerces B to do $X$ in a way that invalidates B's consent only if (1) A proposes or threatens to violate B's rights or not fulfill an obligation to B if B chooses not to do $X$ and (2) B has no reasonable alternative but to accept A's proposal" (Wertheimer and Miller 2008, 390). 
This widely accepted analysis is consistent with some of the guidance on research ethics. For example, the Belmont Report-the foundational ethical document for the human subjects protection system in the Unitd States-states: "Coercion occurs when an overt threat of harm is intentionally presented by one person to another in order to obtain compliance." ${ }^{\prime 3}$ If such an account of coercion is correct, then it follows analytically that paying research participants for participation in research cannot be coercive, since it does not involve any threat. That is, the defining feature of a threat is that it is a proposal to worsen a person's situation, whereas an offer of payment is a proposal to improve a person's situation (relative to not being paid). ${ }^{4}$

On this widely shared analysis, then, offers of payment for research participation are never coercive, regardless of their size. This is not to say that there can be no justified moral concerns about such payments. For instance, low payments might be judged exploitative if they use the recipients' bad circumstances in order to bring about an unfair distribution of benefits and burdens. ${ }^{5}$ Differently, very large payments might be judged problematic if they incentivize people to enroll in multiple studies at the same time, or in studies for which they do not meet the inclusion and exclusion criteria-both of which risk invalidating the data from the studies and increasing the risks to the participants. Nevertheless, this approach suggests that there is no basis for moral concern regarding the coerciveness of such payments specifically, and that the ethical qualms of IRB members, researchers, and others on this score are simply misplaced.

\section{TWO FORMS OF COERCION}

We offer an analysis of coercion that promises to make ethical sense of the widespread concerns about the possible coerciveness of payments, notwithstanding the well-known forceful philosophical arguments to the contrary. According to the view we defend, there are two forms of coercion: consent-undermining coercion and coercion as subjection. ${ }^{6}$ Either or both can be meant by common language uses of the term "coercion."

Consent-undermining coercion is the type of coercion analyzed (correctly) by theorists such as Wertheimer and

3. Note that Wertheimer and Miller think that the relevant baseline for a threat is the coercee's rights, whereas the Belmont Report describes the threat in terms of harm. These are different ways to capture the notion of making someone worse off.

4. We can imagine cases in which someone would be worse off if she enrolled in a study and was paid than if she enrolled in the same study and was not paid. Such unusual cases are not the locus of disagreement between those who think payment can be coercive and those who do not.

5. Relative to some standard of fairness, such as the outcome of an idealized market (Wertheimer 1996).

6 . The discussion in this section closely follows that given in Garnett (2018).
Miller. In this sense, genuine offers are always noncoercive. This is because such offers are never proposals to violate the recipients' rights. In extreme poverty, for instance, the prospective study participants have no prior right to receive any money or assistance from the researchers. The researchers' proposal to pay them $\$ 100$ to enroll on the study (or, equivalently, to fail to pay them $\$ 100$ if they do not enroll on the study) is therefore not a proposal to violate their preexisting rights. It does not worsen their position relative to their existing moral entitlements. Note that this is the case even if the prospective study participants' rights are being violated by others. It may be, for instance, that their government, or the world at large, has a moral duty to alleviate their poverty, such that their continued poverty constitutes a rights violation. But as long as the researchers have no specific duty to alleviate the poverty of these people by means of cash transfers, their proposal is not wrongful and therefore not coercive in the consent-undermining sense. ${ }^{7}$

By contrast, coercion as subjection identifies a respect in which one's life can go badly. Part of what it is to live a flourishing human life is to be free in the sense of not being forced by others to subordinate one's own purposes to theirs. Moreover, it is possible for A to coerce B in this sense-for A to have B over a barrel, so to speak, such that B has "no choice" but to do what A wantseven though A does not strictly speaking propose to violate B's rights and therefore does not coerce B in the consent-undermining sense analyzed by theorists such as Wertheimer and Miller. By way of illustration, consider the following paradigmatic example of a "coercive offer": B is on the brink of starvation; knowing this, A offers B food in return for dangerous and degrading work; seeing no acceptable alternatives, B accepts. Assuming that B has no prior right to A's assistance, A's offer violates none of $\mathrm{B}^{\prime}$ s preexisting rights and is not therefore coercive in the consent-undermining sense. Nevertheless, there remains a respect in which B has no reasonable choice but to submit to A's demands and so is forced to subordinate his own purposes to those of A. That is, B suffers a loss of freedom, understood as a kind of independence from subjection to the foreign wills of others. B is now controlled by A. This is the harm tracked by the idea of coercion as subjection.

Note that this harm may easily be outweighed; indeed, it is likely in this case that B's life goes better, overall, as a result of A's intervention (after all, B does not starve). Nevertheless, there are various specific respects in which $B$ is worse off as a result of the deal. One is that B must now do dangerous and degrading work. Another is that B has been subjected to a foreign will-that is, B undergoes coercion as subjection.

7. Where the research is being carried out by or on behalf of a government, however, it may indeed be the case that the researchers have specific positive duties towards members of the research population. On this, see Mackay (2015). 
To be subjected to a foreign will in this sense is to be (1) forced to act (2) by and in accordance with a will (3) that is foreign to one's own. Less simply, but more precisely:

\section{In doing $x, \mathrm{~B}$ has been subjected to $\mathrm{A}^{\prime} \mathrm{s}$ will if}

1. B does $x$ because it is her only way of avoiding an eventuality that she considers to be unacceptably bad;

2. A has gotten B to do $x$ by helping to make it true that $x$ is B's only way of avoiding this eventuality; and

3. it is not the case that, in getting $\mathrm{B}$ to do $x, \mathrm{~A}$ is motivated only by a set of considerations that also effectively motivates $\mathrm{B}$ to do $x^{8}$

Condition 1 is a forced action condition. It requires that B act because she takes herself to have "no choice" but to do what she does. She has "no choice" in the sense that all other available options are ones she regards as unacceptably bad, whether because of unfortunate circumstances or the acts of others. This condition is met by the patient who consents to surgery so as to avoid death, by the victim who hands his money over to the robber so as to avoid getting shot, and by the worker who accepts dangerous employment so as to avoid starvation. By contrast, however, when a person on an acceptable salary is offered a better-paying job, she is not thereby forced to take it, no matter how irrational it would be to turn it down; and a threat of something trivial, such as pouring your tea down the sink, does not force compliance, even if it happens to be effective. One is forced to act only when one acts so as to avoid an eventuality that one considers to be unacceptably bad. ${ }^{9}$

Condition 2 is an interpersonality condition. It requires that someone else has intentionally gotten $\mathrm{B}$ to act by helping to make it the case that she is forced. Thus, a storm may force me to cancel my boat trip (I consider drowning to be unacceptably bad), but I am not thereby subject to a foreign will. One cannot be subject to a nonexistent will. This is not to deny that forced action is bad in itself: Generally, our lives go better when we are able to chart our own courses from a range of acceptable options. Nevertheless, interpersonal subjection is worse, for in these cases we are not only forced to act, but forced to subordinate our own purposes to those of another.

Finally, condition 3 is a nonconformity of wills condition. It holds that if the reasons for which $\mathrm{A}$ gets $\mathrm{B}$ to act

8. This analysis leaves out a number of complexities, including those arising from the possibility of bluffs. For a more complete version, see Garnett (2018).

9. For helpful analysis of this idea in the context of exploitative offers, see Mikhail Valdman's analysis of "unacceptable nontransaction costs" (Valdman 2009, 9-10). are fully subsumed by the reasons for which B acts, then A's will is not relevantly foreign to B. To illustrate: Suppose that A gives B some desperately needed money out of charity. In accepting the gift, it may be that B is thereby forced to comply with A's will. Yet B is not subjected to a foreign will. This is because A's aim in getting $B$ to accept the gift, and B's aim in accepting it, are precisely the same: improvement of B's financial situation. Where this conformity in wills obtains, then, there is no subjection to a foreign will. ${ }^{10}$

Note that interpersonal subjection may come in degrees. For example, if A's and B's wills are in substantial but imperfect conformity, B may be subject to A's will but only to a small degree. ${ }^{11}$ Thus suppose that in addition to (genuinely) wanting to help B with her charitable gift, A also aims to impress $C$ with her generosity-an additional aim not shared by $B$. In this case, B is strictly speaking subjected to A's will: In effect, A forces $B$ to help her to look good. Nevertheless, if impressing C plays a relatively minor motivational role for $\mathrm{A}$ compared with the aim of helping $B$, then A's will may still be in substantial conformity with B's, and B may therefore be subjected to a relatively minor extent. By contrast, if $\mathrm{A}^{\prime}$ s main purpose is to impress C, with benefitting $B$ merely an afterthought, then B may be subjected to a relatively large extent. In short: To the extent to which $\mathrm{A}$ acts for reasons shared by $\mathrm{B}, \mathrm{B}$ is to that extent not subject to A's foreign will.

To be subject to a foreign will, therefore, is to be forced to subordinate one's own purposes to the unshared purposes of another. To be coerced is to be subjected to a foreign will to some significant extent. On our analysis, coercion as subjection therefore substantially overlaps with, but is nevertheless importantly distinct from, the consent-undermining coercion analyzed by theorists such as Wertheimer and Miller. ${ }^{12}$ Specifically, while the two types of coercion typically coincide in standard threat cases like that of the armed robber (who both proposes to violate your rights and subjects you to her foreign will), they frequently come apart in cases involving what might be termed "coercive offers." It is to the latter that we now turn.

10. This means that whether or not someone is coerced in this sense depends on the subjective mental states of both partiesif in fact they act for the same reasons, then there is no coercion. Likewise, whether the person being coerced feels as though she is coerced will partly depend on why she thinks the coercer is acting.

11. The degree of interpersonal subjection may depend also on (a) the badness of the unacceptable alternative and (b) the specificity of $x$.

12. That coercion as subjection does not suffice by itself for a failure of consent is shown by the case of the appendectomy, discussed in the preceding: One is able to give valid consent to such a procedure, despite the fact that in doing so one may be subject to the foreign will of the surgeon. See also the case of natural history, discussed in the following. 


\section{COERCION AS SUBJECTION AND PAYMENT FOR RESEARCH PARTICIPATION}

To see the relevance of distinguishing these two senses of coercion in the context of payment for research participation, return to the case of extreme poverty. As we saw in the first section, there appears to be deep and widespread disagreement within the research ethics community about whether cases like this involve coercion. This disagreement may be understood and resolved, we claim, by taking its parties to be concerned with distinct forms of coercion that carry different kinds of moral force. ${ }^{13}$

Assuming that the researchers do not have a prior duty to give the prospective participants $\$ 100$, the offer of payment is not coercive in the consent-undermining sense. The proposal to give them $\$ 100$ conditional on taking part in the hypertension study does not violate their preexisting rights, and is not a threat but an offer. It is therefore not coercive in a sense that undermines the voluntariness or the validity of the participants' consent.

However, if there are no viable alternative ways for a prospective participant to alleviate his poverty, it is very likely that the payment involves coercion as subjection. In particular, it will involve such coercion whenever the following are true (each corresponds to one of the conditions of the account presented in the third section):

1. The participant enrolls in the study because this is his only way of avoiding an eventuality that he considers to be unacceptably bad (e.g. the unmitigated effects of continued dire poverty);

2. the researchers have gotten the participant to enroll in the study by helping to make it true, by making their offer, that enrolling is the participant's only way of avoiding continued dire poverty; and

3. in getting the participant to enroll, the researchers are not motivated by a set of considerations that also effectively motivate the participant to enroll (e.g., the researchers are motivated by scientific considerations, whereas the participant is motivated by financial considerations).

It is highly plausible to suppose that all of conditions 1-3 hold with respect to the majority of participants in

13. More specifically, our view is that ordinary (nonphilosophical) talk about coercion is generally ambiguous with respect to the two underlying moral concepts distinguished here, i.e., consent-undermining coercion and coercion as subjection. While previous philosophical work on the topic has succeeded in isolating the first of these and making it precise, this article aims to do the same with the second. In both cases, some revision of ordinary usage is unavoidably required. Thus, our claim is not that people have all along been employing one concept (coercion as subjection) in a fully coherent way while philosophers have been mistakenly analyzing a different one (consent-undermining coercion). It is that people have been semi-incoherently employing a mixture of both concepts, and that the best way of making philosophical sense of this is by providing a clear account of the two and the relationship between them. the case of extreme poverty. This analysis therefore vindicates the REC chair's view that the payment would be coercive in a morally relevant sense.

However, payment for research participation will rarely meet all three conditions. In many cases, condition 1 will not be met: that is, participants will not take participation to be their only way of avoiding unacceptable alternatives. Consider the following case:

Challenge study. A U.S. medical center is enrolling healthy volunteers between 18 and 30 for an influenza challenge study to characterize the natural history and pathogenesis of human influenza virus. Participants remain as inpatients for up to 10 days and undergo a variety of invasive and noninvasive tests. The study pays $\$ 5000$. Most participants are expected to be college students.

Studies like this also tend to provoke ethical concern. Participants are paid a substantial amount of money to take on the risks and burdens of the study, and it would be wishful thinking to suppose that any would be in the study were it not for the money. However, we judge it unlikely that the payment would be coercive. For most students in high-income countries the alternative to receiving $\$ 5000$ might be markedly worse-they might have to take on more student debt or work a job they would rather not do-but these are not alternatives that they are likely to consider unacceptable in the relevant sense. ${ }^{14}$ Such studies are therefore not typically coercive in either the consent-undermining sense or the subjection sense, and concerns about their coerciveness are indeed misplaced.

In other cases, condition 3 will not be met: that is, participants will have motives for enrolling in the study that align with the motives of the researchers. As an example, consider the following:

Phase 1 treatment study. An academic medical center is enrolling patients in the late stages of a rare degenerative neurological disorder into a phase 1 study. The study gives participants escalating doses of an experimental treatment in order to ascertain the drug's dose-limiting toxicity. Benefit is possible, but unlikely. Nevertheless, patients with the disorder are eager to enroll. It is a close-knit patient population and many of them are highly committed to developing a cure for future sufferers.

In this case, participants have no good alternatives to study participation, since there are no proven treatments for their condition and they are expected to die without intervention. However, offering the option of study participation does not constitute coercion as subjection because the researchers' aim in getting the patients to enroll matches one of the patients' central aims in

14. Of course, there may be individual exceptions, such as someone with pressing debts to pay off or someone who would have to drop out of college without the money. 
enrolling: benefit to future patients. This conformity of wills between the patients and the researchers means that although the patients have "no choice" but to comply with the researchers' wills, those wills are not relevantly foreign to their own. ${ }^{15}$

\section{FROM BAD TO WRONG?}

We have argued that coercion as subjection is bad for the person who is coerced: All else being equal, one's life goes better when one is not subjected to a foreign will. But the fact that it is in one respect bad for someone to be subjected to a foreign will does not entail that all acts of coercion as subjection are wrongful.

In most philosophical and bioethical treatments of the coerciveness (or otherwise) of payment for research participation, the moral significance of coercion is taken to bear on consent. That is, in these discussions the question "Is payment coercive?" is taken to be morally important insofar as it bears on the question "Does payment invalidate consent?" But the type of coercion that has this moral force is the consent-undermining type and, for reasons we reviewed in the preceding, payment is generally not coercive in this sense.

The moral force of coercion as subjection, by contrast, is not that it undermines consent. Instead, it is that it constitutes a particular kind of harm. In this sense, the question "Is payment coercive?" is morally important inasmuch as it bears on the question "Is there a respect in which payment is bad for the research participants?"

RECs routinely make assessments of the expected harms and benefits of the studies they review and may prohibit studies that they deem excessively risky, even when the participants are all anticipated to be consenting adults. However, the fact that a study poses some risk to participants is not regarded as sufficient reason to disallow it. A research study can be ethical if either the risks to participants are outweighed by the expected benefits or the net risks to participants are justified by the social value of the knowledge that is expected to result. Thus, the mere fact that a research study is or is likely to be harmful to its participants in certain respects does not automatically render that study unethical.

Coercion as subjection is no different from other harms in this respect: Some acts that are coercive in this

15. Of course, this conformity of wills is unlikely to be perfect. The researchers may have various ancillary motives, such as publication or career advancement, that are not shared by the participants. Nevertheless, to the extent to which these are comparatively minor motivations relative to the aim of benefitting future sufferers, the degree of interpersonal subjection will be low. By contrast, if the researchers cared very little about future patients and were, in effect, using participants and their vulnerabilities primarily as tools for their own career advancement, the degree of interpersonal subjection would be high and the case would likely involve coercion as subjection. sense are nevertheless clearly permissible. To see this, consider the following:

Natural History. A natural history study is enrolling people with HIV/AIDS who have low CD4 counts. They are put onto antiretroviral treatment and their progress is monitored. One of the primary research objectives is to collect samples from different groups of patients with immune disorders in order to conduct research on genetic and cellular differences between people with immune disorders and those without. Anonymized data from participant medical records are analyzed but there are no invasive study interventions. Many of the study participants are uninsured or underinsured and would not be able to access treatment elsewhere.

Any patient who both (a) is unable to access antiretroviral therapy outside of the study and (b) has little interest in the success of the researchers' immune disorder study very likely participates in the study under coercion as subjection. This is because:

1. The patient participates in the study because this is his only way of avoiding an eventuality he considers to be unacceptably bad, that is, not receiving lifesaving treatment;

2. the researchers have gotten the patient to participate by helping to make it true that participation is his only way of receiving lifesaving treatment, that is, by offering free treatment as part of the study; and

3. it is not the case that, in getting the patient to participate, the researchers are motivated by a set of considerations that also effectively motivate the patient to participate-that is, the researchers aim to study immune disorders, whereas the patient aims to benefit from treatment.

Participants are coerced in the sense that they are forced to comply with purposes of others that they do not share: Unless they assist the researchers in their immune disorder project, they will likely die, and in this respect the researchers effectively use the participants as tools for their project. Yet although the study involves coercion as subjection it seems obviously permissible. Natural history shows that the badness of coercion as subjection can be outweighed by benefits to participants on other dimensions of well-being, and that sometimes this will render the harm of interpersonal subjection permissible overall. ${ }^{16}$ Indeed, given the size and nature of the benefits to the participants, the conduct of the

16. Note that we have not said anything here about how to assess the magnitude of the harm involved, but rely on the intuitive judgment-which we would expect to be shared by REC members and participants-that the benefits are easily enough to outweigh the harms. In more contested cases, it might be that the views of potential participants should be elicited in order to ascertain how they value the potential harm of subjection. 
researchers in this case is not only morally permissible, but most likely praiseworthy as well. ${ }^{17}$

Return now to the case of extreme poverty. In this case, too, it is reasonable to suppose that the harm of coercion-that is, the harm to participants of being put in a position in which they are effectively forced to do as the researchers wish-is outweighed by the benefits of participation (in this case, receipt of \$100). Certainly, we may presume that those who enroll in the study take this to be the case, or else they would not enroll; that is, any prospective participant could prioritize her freedom over material improvement simply by declining the offer. But from the fact that the study is overall beneficial to its participants, does it follow that the study is ethically permissible?

It does not. Independent of the question of coercion, in performing a risk-benefit assessment for a proposed study, we cannot simply aggregate the expected benefits and harms and judge the study permissible whenever it has expected net benefits for participants. This approach would not ensure that risks are minimized or that the risks of individual research procedures are justified by the value of the knowledge to which they contribute. For example, suppose a researcher proposed to perform a liver biopsy on a subset of her research subjects on the speculative off-chance that she would find something interesting. This would generally be considered unethical even if the balance of harms and benefits for participants were still positive overall, since the extra risky procedure would be unlikely to provide much of value. Thus, a package of harms and benefits can be beneficial on balance, but still wrongful. This means that although the coercion in extreme poverty is almost certainly beneficial on balance to the participants overall, it may nevertheless constitute a sufficiently serious harm in itself to raise problems about its permissibility. What, then, should the research team and its sponsor do?

Three responses seem reasonable: We call them "acceptable alternatives," "shared goals," and "ample benefits."

\section{Acceptable Alternatives}

First, researchers might seek to avoid a significant risk of coercion by conducting their studies in populations where potential participants are likely to have acceptable alternatives to enrolling in the study. Assuming they have no prior obligation to conduct their research

17. For a more challenging case, see Jerry Menikoff and Edward P. Richards's description of how U.S. pediatric oncologists have collectively decided to refuse to offer patients new treatments that are comprised of novel combinations of already approved drugs except through clinical trials (Menikoff and Richards 2006, 239-251). If their description is accurate, it is plausible that parents are coerced into enrolling their children into clinical trials. Defenders of the trials would have to argue that the harm of this coercion is outweighed by the social value of the knowledge gained through the research. in a particular disadvantaged population, then conducting the research in a population that was not in such desperate need (such as that in the challenge study), or screening prospective participants with respect to whether payment would be coercive would mostly allow them to avoid coercion as subjection. ${ }^{18}$ This response will often come at an ethical cost, however. It is likely to lead to the withholding of benefits from precisely those individuals and groups who would benefit from them most.

\section{Shared Goals}

Second, researchers might seek to avoid the risk of coercion by conducting their studies in populations where potential participants are likely to share in the goals of the research. Even when such studies also involve payment for participants, coercion will be absent insofar as participants are also motivated to enroll in order to further the aims of the research. This is because the wills of the participants and the researchers will be in relative conformity. Conducting these kinds of studies where possible is another way in which researchers could mostly avoid coercion as subjection. ${ }^{19}$

\section{Ample Benefits}

Third, researchers might pursue a strategy not of avoidance but of increasing benefits. Recall that consentundermining coercion automatically renders a proposal morally impermissible, whereas coercion as subjection preserves consent but introduces a partial setback to participant interests. Moreover, in cases where the total package of potential harms (including the harm of coercion) is amply outweighed by the potential benefits of participation (as in natural history), the presence of coercion as subjection need not render a study morally impermissible, and can even be consistent with a study

18. Note that although neither necessary nor sufficient for an absence of coercion as subjection, the fact that a study has been conducted without any offer of payment, or of only certain forms of "token" payment, is in general a reliable indicator that participants have not been coerced to enroll. Payment that simply covers participants' costs (such as parking charges) offers no net economic benefit to participants, and therefore cannot constitute any means, let alone a sole means, of avoiding unacceptable economic alternatives. Those who enroll in such studies, then, do so for reasons other than their having no acceptable alternative. Similar considerations apply to payment by means of gift cards that are redeemable for nonessential items, such as movie tickets. (By contrast, voucher payments in terms of, say, food stamps most likely would raise legitimate concerns about coercion.) Our analysis might therefore explain why many of the Largent et al. respondents thought that a "substantial payment" was more of a source of concern than a "token payment."

19. This then provides a reason in favor of research that is "responsive to the health needs or priorities of the communities or populations where the research will be conducted" (CIOMS 2016, Guideline 2). 
being morally praiseworthy. Researchers would still have to ensure that they had minimized the risks and that the risks of individual procedures were justified by the value of the knowledge to which they contributed. But they might then seek to ensure that research participants are amply compensated for the coercion as subjection that they undergo.

In the case of natural history, the outweighing benefits are medical (receipt of antiretroviral treatment). Yet in other studies, an alternative source of compensating benefit can be payment itself. That is, the very source of the coercion-the incentive that gives the participants "no choice" but to enroll in the study-can also, if substantial enough, be what renders that coercion morally permissible by amply compensating for its harm. So researchers pursuing this third strategy should ensure that payments, when necessary, are relatively substantial.

This result runs contrary to a common view, this being that larger payments are likely to be more coercive and that the risk of coercion is minimized by reducing the size of the payment. For instance, the data on IRB members' views suggests that where they think payment may be coercive, they also think that higher payment makes the risk of coercion greater. According to the analysis we have given, however, this response is mistaken. Whether someone is a victim of coercion as subjection is a function of how bad the alternative to a proposal is, not how good the proposal is in itself. Someone who is so desperate for money that she will do dangerous, degrading work for a dollar a day is no less subject to the will of her employer than someone who would only do the work for more than $\$ 100$.

Not only is it false that reducing the level of payment reduces the level or risk of coercion, it is also plausible that one way to compensate for coercion as subjection is to increase the payment. From the point of view of the participants, they are worse off to the extent that they are subject to the will of others, but better off to the extent that they receive benefits in virtue of enrolling in the study. More money helps to offset the negative effect of coercion, even though the payment is itself the source of the coercion.

It might be objected that the payments to participants should not be regarded as reducing the harmfulness of coercion on the grounds that monetary benefits are not supposed to be taken into account by RECs when they conduct their risk/benefit assessments. ${ }^{20}$ There is room for debate over whether this widespread view about monetary benefits is justified (Wertheimer 2013). In any case, we think such an objection would miss the mark. The claim that monetary benefits should not be taken

20. For example, the Institutional Review Board Guidebook states: "Direct payments or other forms of remuneration offered to potential subjects as an incentive or reward for participation should not be considered a 'benefit' to be gained from research" (OHRP 1993, chap. 3). into account is intended to rule out weighing payment against the risks of study procedures, such as the side effects of a drug. We do not take a view on that question here. We contend only that increased payment can compensate for the setback to interests that the payment itself may cause (through the way that the inducement may lead participants to be subject to the foreign will of the researchers). It would be perverse not to assess the benefits of an inducement when evaluating the harms of that very inducement. Analogously, consider that RECs are encouraged to consider the potential economic harms arising from research participation (National Commission for the Protection of Human Subjects of Biomedical and Behavioral Research 1979). These might include, for example, additional treatment costs resulting from research interventions. It is widely accepted that these financial risks can be mitigated or compensated for by providing care, or by paying for insurance or the cost of care (Presidential Commission for the Study of Bioethical Issues 2011, 56-62).

\section{UNDUE INDUCEMENT}

In the research ethics literature the concepts of coercion and undue inducement (or undue influence) are frequently mentioned together. However, while coercion has been the subject of substantial scholarly discussion, undue inducement has received much less attention. The literature suggests three ways to conceive of undue inducement.

First, undue inducement may occur when someone is presented with an incentive that undermines her ability to make autonomous decisions. As Wertheimer and Miller put it: "As a general category, an inducement is undue only when it predictably triggers irrational decision-making given the agent's own settled (and reasonable) values and aims" $(2008,391)$. If an inducement had this effect on someone's ability to make a decision about enrollment into a research study, it would undermine the validity of her consent in virtue of its effects on her capacity to consent.

Second, some commentators focus specifically on the effect of incentives on people's judgments about risks. For example, Ezekiel Emanuel writes: "Undue inducement is when we offer people goods to assume clearly excessive and unreasonable risks" (Emanuel 2005, 11). If undue inducements are incentives that lead people to take on unreasonable risks, then a further reason for RECs to be concerned about them is paternalistic: It is within the mandate of the REC to prohibit studies that are excessively risky for participants.

Insofar as "undue inducement" is used to refer to a putative effect of inducements on potential research participants' ability to reason, it falls outside the scope of our discussion here. We note only that there is no evidence that payment leads to people making worse 
decisions; if anything, the evidence points in the other direction. $^{21}$

A third conception is implicit in the treatment of coercion and undue inducement by guidelines and REC members. This conception treats coercion and undue inducement as lying on a continuum. ${ }^{22}$ As Klitzman notes: "IRBs also tend to use the terms coercion and undue influence interchangeably" (Klitzman 2013, 226). Of course, such a conception simply reveals confusion if the only correct way to understand coercion is as consent-undermining coercion. But if, as we suspect, the language of "coercion" is also used to mark coercion's role in controlling someone's behavior, the continuum view makes sense. In the context of payment for research participation it may be that "coercion" and "undue influence" are frequently used to pick out the same morally problematic phenomenon-coercion as subjection. As we have argued, however, it is a mistake to think that the presence of this phenomenon automatically renders a research study morally impermissible.

\section{EXPLOITATION AND COERCION}

On one widely accepted analysis, exploitation occurs when one party takes unfair advantage of another: Specifically, A exploits B when A takes advantage of some vulnerability of B's in order to gain an unfair level of benefits (Wertheimer 1996). ${ }^{23}$ In the context of health research, participants who are poor or in desperate need of clinical care may be vulnerable to exploitation by researchers and (indirectly) their sponsors. For example, a pharmaceutical company might pay a pittance to the participants in the clinical trials that lead to the marketing approval for a blockbuster drug. If it gets away with paying them so little because they are poor and lack other options for making money, then it may well be exploiting them (Millum 2012).

Exploitation and coercion as subjection often play upon similar vulnerabilities and so overlap substantially. If coercion as subjection is normally wrongful only when the compensating benefits are low relative to the harm of interpersonal subjection-as we have been

21. Bentley and Thacker (2004) found that higher payments increased participants' willingness to enroll in a hypothetical study but did not appear to blind them to risk. Halpern et al. (2004) found no effect of level of payment on patient perceptions of the risks of a hypothetical study. In their comparison of the effects of short and long consent forms, Stunkel et al. report that "volunteers who reported a primary financial motivation had significantly greater comprehension compared to volunteers with a primary nonfinancial motivation" (Stunkel et al. 2010, 6).

22. This corresponds to what Largent et al. call the "sliding scale view" (Largent et al. 2013, 506).

23. For alternative analyses, see, e.g., Valdman (2009) or Vrousalis (2013). Note that the overlap between coercion as subjection and exploitation may be even greater on such views than on the standard one. suggesting - then coercion as subjection will normally be exploitative in just those cases in which it is also wrongful. This is because paying a poor person only just enough to motivate them to participate in a research study normally qualifies as taking unfair advantage of their poverty.

These considerations help to explain why a number of theorists have been tempted by the thought that offers are coercive only when they are exploitative. ${ }^{24}$ Yet despite the frequent overlap, the wrong of exploitation is nevertheless different from the wrong of coercion as subjection. To see this, note that a research study could be conducted despite bringing only very minimal net benefit to the researchers. In such a case, it is possible that the pittance paid to the research participants might not constitute an unfair distribution of the burdens and benefits of the study, and thus not involve the researchers taking unfair advantage of the participants' desperate situation. Yet the transactions may still have involved coercion as subjection because the participants were subject to the will of the researchers. Such a study might then be morally impermissible in view of the inadequately compensated coercion, without being exploitative.

We noted in the preceding that one way to render coercion as subjection nonwrongful, on balance, is to provide greater compensating benefits. In the context of coercive payments, this might involve increasing the level of payment. As others have noted, this is also a way to ensure that a transaction is nonexploitative (Ballantyne 2008). Provided that the parties to a transaction receive a fair level of benefits, the transaction cannot involve taking unfair advantage. Thus, providing higher levels of payment may both compensate for the coerciveness of a transaction and help to render it nonexploitative.

\section{IMPLICATIONS}

Payment for participation in medical research can be coercive. While it is unlikely to be coercive in the sense of undermining the voluntariness, and hence the validity, of participants' consent, it may well be coercive in the sense of constituting a specific kind of setback to participants' interests-that of subjection to a foreign will. Contrary to the prevailing wisdom in the bioethics and philosophy literature, REC members who raise concerns about coercion in the context of payment are not making a simple conceptual error, but may be identifying a genuine ethical issue, albeit imprecisely. We have tried to make that concern more precise. Our analysis in this article can help diagnose what underlies ethical worries that are raised about payment for research participation. Only once the underlying issue is identified-whether it be consent-undermining coercion, coercion as subjection,

24. See, e.g., Frankfurt (1973), Feinberg (1983), and Haksar (1976) (all quoted in Wertheimer 1987, 226-227). 
undue inducement, or exploitation-can an appropriate recommendation be made about how to address it.

When it comes to addressing coercive payments, we emphasize three points that researchers, RECs, and regulators should bear in mind.

First, and contrary to the views of most people who raise the issue of coercive payments, the size of the payment does not matter to whether an agreement is coercive. What matters is whether turning down the offer of payment will leave a prospective participant in an unacceptable situation. If it will not-if the prospective participant is not in desperate financial need-then even a large offer of payment will not be coercive. If it willif the prospective participant has, in effect, "no choice" but to accept the offer-then even a small offer may be coercive, and a larger one will be no more coercive than a smaller one. RECs should not require reduced payments in order to reduce the risk of coercion.

Second, the fact that an offer is coercive in this sense does not entail that it is wrongful. Unlike with consentundermining coercion, the fact that a study may involve coercion as subjection does not render it automatically impermissible. Instead, the harm of coercion must be balanced with the other potential harms and benefits of the study.

Third, if researchers judge that a study is likely to involve coercion as subjection there are three ethically acceptable options. The first is to relocate the study to a population that is less likely to be in financial hardship ("acceptable alternatives"). This option has the disadvantage of depriving people in desperate need of important benefits. The second is to relocate or redesign the study so that the population from which participants are drawn is more likely to share in the aims of the research ("shared goals"). The third is to compensate for the coercion as subjection by ensuring the benefits to participants are sufficiently high, which might involve raising the level of payment ("ample benefits"). Which of these responses is most appropriate in a given case must, of course, be judged with reference to the details of that case.

\section{DISCLAIMER}

The views expressed are the authors' own. They do not represent the position or policy of the National Institutes of Health, the U.S. Public Health Service, or the Department of Health and Human Services.

\section{REFERENCES}

Ballantyne, A. 2008. Benefits to research subjects in international trials: Do they reduce exploitation or increase undue inducement? Developing World Bioethics 8(3): 178-191. doi: 10. 1111/j.1471-8847.2006.00175.x.

Bentley, J. P., and P. G. Thacker. 2004. The influence of risk and monetary payment on the research participation decision making process. Journal of Medical Ethics 30(3): 293-298. doi: 10. 1136/jme.2002.001594.

Berman, M. N. 2002. The normative functions of coercion claims. Legal Theory 8(1): 45-89. doi: 10.1017/S1352325202081028.

Council for International Organizations of Medical Sciences (CIOMS) in collaboration with the World Health Organization (WHO). 2016. International ethical guidelines for health-related research involving humans. 4th ed. Geneva: CIOMS.

Emanuel, E. J. 2005. Undue inducement: Nonsense on stilts? The American Journal of Bioethics 5(5): 9-13. doi: 10.1080/ 15265160500244959 .

Frankfurt, H. G. 1973. Coercion and moral responsibility. In Essays on freedom of action, ed. T. Honderich. London: Routledge and Kegan Paul.

Feinberg, J. 1983. Noncoercive exploitation. In Paternalism, ed. R. Sartorius. Minneapolis: Minneapolis University Press.

Garnett, M. 2018. Coercion: The wrong and the bad. Ethics 128(3): 545-573. doi: 10.1086/695989.

Halpern, S. D., J. H. T. Karlawish, D. Casarett, et al. 2004. Empirical assessment of whether moderate payments are undue or unjust inducements for participation in clinical trials. Archives of Internal Medicine 164(7): 801-803. doi: 10.1001/archinte.164.7.801.

Haksar, V. 1976. Coercive proposals [Rawls and Gandhi]. Political Theory 4(1): 65-79. doi: 10.1177/009059177600400106.

Klitzman, R. 2013. How IRBs view and make decisions about coercion and undue influence. Journal of Medical Ethics 39(4): 224-229. doi: 10.1136/medethics-2011-100439.

Largent, E. A., C. Grady, F. G. Miller, and A. Wertheimer. 2012. Money, coercion, and undue inducement: A survey of attitudes about payments to research participants. IRB 34(1): 1-8.

Largent, E., C. Grady, F. G. Miller, et al. 2013. Misconceptions about coercion and undue influence: Reflections on the views of IRB members. Bioethics 27(9): 500-507. doi: 10.1111/j.1467-8519. 2012.01972.x.

MacKay, D. 2015. Standard of care, institutional obligations, and distributive justice. Bioethics 29(4): 262-273. doi: 10.1111/bioe.12060.

Macklin, R. 1989. The paradoxical case of payment as benefit to research subjects. IRB: Ethics \& Human Research 11(6): 1-3.

Menikoff, J., and E. P. Richards. 2006. What the doctor didn't say: The hidden truth about medical research. New York: Oxford University Press.

Millum, J. 2012. Sharing the benefits of research fairly: Two approaches. Journal of Medical Ethics 38(4): 219-223. doi: 10. 1136/medethics-2011-100118.

National Commission for the Protection of Human Subjects of Biomedical and Behavioral Research. 1979. The Belmont report: Ethical principles and guidelines for the protection of human subjects of research. Washington, DC: Department of Health, Education, and Welfare.

Office for Human Research Protections. (OHRP). 1993. Institutional review board guidebook, chapter 4. http://archive. hhs.gov/ohrp/irb/irb_chapter4.htm 
Presidential Commission for the Study of Bioethical Issues. 2011. Moral science: Protecting participants in human subjects research. https://bioethicsarchive.georgetown.edu/pcsbi/node/ 558.html

Ryan, C. C. 1980. The normative concept of coercion. Mind 89(356): 481-498. doi: 10.1093/mind/LXXXIX.356.481.

Stunkel, L., M. Benson, L. McLellan, et al. 2010. Comprehension and informed consent: Assessing the effect of a short consent form. IRB 32(4): 1-9.

U.S. Food and Drug Administration (USFDA). 2016. Payment to research subjects - information sheet. http://www.fda.gov/ RegulatoryInformation/Guidances/ucm126429.htm.

Valdman, M. 2009. A theory of wrongful exploitation. Philosophers' Imprint 9(6): 1-14.
Vrousalis, N. 2013. Exploitation, vulnerability, and social domination. Philosophy \& Public Affairs 41(2): 131-157. doi: 10. 1111/papa.12013.

Wilkinson, M., and A. Moore. 1997. Inducement in research. Bioethics 11(5): 373-389.

Wertheimer, A. 1987. Coercion. Princeton, NJ: Princeton University Press.

Wertheimer, A. 1996. Exploitation. Princeton, NJ: Princeton University Press.

Wertheimer, A. 2013. Is payment a benefit? Bioethics 27(2): 105-116. doi: 10.1111/j.1467-8519.2011.01892.x.

Wertheimer, A., and F. G. Miller. 2008. Payment for research participation: A coercive offer? Journal of Medical Ethics 34: 160-164. 